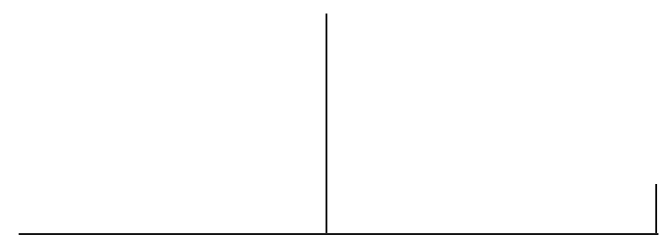

Rev. Latinoam. Psicopat. Fund., São Paulo, v. 12, n. 2, p. 417-421, junho 2009

James C. Harris. "The Convalescent", Archives of General Psychiatry, v. 66, n. 1, p. 10-11, Jan. 2009.

James C. Harris. "Bernagchen Mahakala", Archives of General Psychiatry, v. 66, n. 2, p. 122-123, Feb. 2009.

James C. Harris. "The Art of Painting" Archives of General Psychiatry, v. 66, n. 3, p. 234-235, Mar. 2009.

James C. Harris. "Hagia Sophia (Divine Wisdom)" Archives of General Psychiatry, v. 66, n. 4, p. 353-354, Apr. 2009.

James C. Harris. "Christina's World" Archives of General Psychiatry, v. 66, n. 5, p. 466-467, May 2009.

Peter J. Buckley. "Francisco José de Goya y Lucientes, 1746-1828" The American Journal of Psychiatry, v. 166, n. 3, p. 292, Mar. 2009.

Aaron H. Esman. "Alfred Kubin, 1877-1959"

The American Journal of Psychiatry, v. 166, n. 5, p. 529, May 2009.

\title{
"Imagens sem peso"
}

Guilherme Gutman

Em cada uma das revistas que nós - psiquiatras, psicólogos e psicanalistas - habitualmente lemos há certas seções que podem, à primeira vista, parecer de menor estatura, isto é, secundárias em relação a outras nas quais os temas abordados pareceriam mais "nobres". Talvez se pareçam um pouco com aquele cômodo sobressalente em uma casa de muitos e bem guarnecidos quartos; eternamente à espera de um hóspede improvável que, finalmente, se serviria de seu mobiliário modesto. Ou talvez tenha status similar àque- 


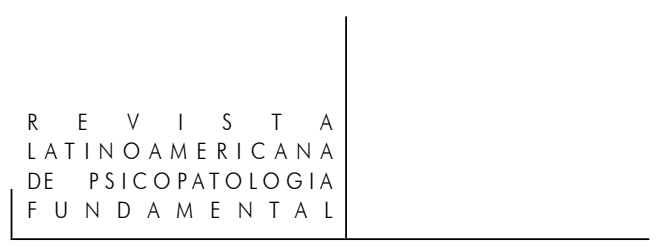

las disciplinas de certos cursos universitários - medicina, por exemplo - que parecem ocupar com timidez certas brechas porventura não preenchidas pelas disciplinas "pesos pesado" tais como anatomia ou fisiologia. A própria psiquiatria é o depoimento de alguns psiquiatras - parece ocupar um lugar meio gauche quando comparada a especialidades "mais médicas" como seria o caso, entre outras, da cardiologia, da neurologia ou da cirurgia geral.

Essas pequeninas seções são em geral pouco lidas: da mesma forma que, pressionado pelas exigências acadêmicas das matérias de maior importância, o futuro médico raramente abrirá o livro de "psicologia médica" ou de "saúde da comunidade", salvo já tenha sido irremediavelmente mordido pela sedução underground dessas outras disciplinas.

Alguns desses potenciais leitores não sabem o que perdem; outros, sabem exatamente o que deixam "para depois", mas o cansaço, o elenco de prioridades ou mesmo a preguiça acabam fazendo do "depois" um "nunca". A estes últimos desejamos fôlego. Aos primeiros, a recomendação (gasta?) de um permitam-se algumas voltas por caminhos vicinais e não apenas pelas estradas principais.

Tomemos o exemplo das boas revistas. Na Archives of General Psychiatry há uma seção intitulada "Art and Images in Psychiatry". À primeira vista, a presença de algo referente à arte em um periódico médico pode parecer apenas um recreio entre as exigentes aulas de psiquiatria clínica e psicofarmacologia: um passeio pelo bosque, uma partida de futebol na quadra do colégio, uma conversa descompromissada no pátio ou um lanche na cantina. Mas, tantos anos distantes do ambiente escolar, ao olharmos para trás, quais são as nossas melhores memórias? Minha hipótese é a de que neste fora-de-sala-de-aula, as lembranças foram marcantes exatamente porque neste segmento da vida de estudante aprendemos coisas que, se não são parte de um currículo formal, também não são completamente estrangeiras à idéia do que se aprende na escola. Em outras palavras, é neste dentro-fora que, então, entrelaçávamos o conhecimento adquirido à vida vivida.

A sugestão aqui é clara: as seções secundárias poderiam ser uma oportunidade para alguns desvios necessários. Nestes, nos distanciaríamos um pouco das disciplinas-mãe para, por caminhos inesperados e por ângulos insuspeitos, reencontrarmos algo novo sobre a clínica.

Digo que as seções "poderiam ser uma oportunidade" porque ao ler os cinco artigos publicados este ano na referida seção da Archives, não encontrei nada muito estimulante. Ao contrário, durante a leitura não tive uma impressão muito boa, pois senti que o espírito da coluna era exatamente o de uma espécie de descanso para olhos cansados de artigos sérios. Nesse sentido, o maior problema me pareceu ser a posição em que a arte era colocada: como um domínio completamente estrangeiro à psiquiatria ou à psicanálise em relação ao qual olharíamos 
como quem vai a um museu atento às informações mastigadas por um guia profissional, à espera de uma história curiosa e, quem sabe, a sorte de alguma interseção - um artista que enlouqueceu ou uma representação pictórica da melancolia - com os assuntos psi. Este domínio estrangeiro é olhado com uma condescendência inadequada ou, simplesmente, como algo que ilustre, exemplifique ou, na melhor das hipóteses, amplifique um conhecimento já estabelecido.

\section{Passeando pelo museu}

Vejamos brevemente algumas das conclusões produzidas nesses artigos da Archives.

Em "The Convalescent", há a apresentação da confluência entre a vida e a obra da pintora finlandesa Helene Schjerfbeck (1862-1946). Naturalmente este é um dos tópicos fundamentais nas interseções entre arte e sofrimento psíquico, mas a abordagem do tema feita por Harris é bastante naïf, do tipo suas-dores-transplantadas-para-a-tela.

Em "Bernagchen Mahakala” há uma ligeiríssima passada por Jung e suas mandalas, além da sugestão - supostamente embasada por justificativas técnicas - dos efeitos terapêuticos da meditação e outras práticas budistas.

Já em "The Art of Painting” temos, possivelmente, a história mais interessante: um falsário holandês - Han van Meegeren (1889-1947) - que produziu um "autêntico" Vermeer (1632-1675) adquirido em 1943 por ninguém mais ninguém menos que Hermann Göring, o comandante nazista que, seguindo os passos do führer, "era conhecido por confiscar ou adquirir arte maior e por imaginar ser um connoisseur" (p. 234). Já prisioneiro em Nuremberg, e antes de cometer o suicídio, soube que a peça central de sua coleção de arte era uma fraude e neste momento, segundo relatos, olhou "como se pela primeira vez tivesse descoberto o mal no mundo". Interessante, não. Contudo, mais uma vez, o autor extrai conclusões superficiais sobre a criatividade.

Em "Hagia Sophia” e em "Christina’s World” temos, respectivamente, uma reflexão rápida sobre o valor da religião e o impacto da vida de sua retratada sobre a vida do pintor norte-americano Andrew Wyeth (1917-2009).

Nos dois artigos publicados este ano no The American Journal of Psychiatry, em uma seção intitulada "Images in Psychiatry", similar à da Archives, não encontrei nada muito diferente. Talvez algo ainda mais modesto, posto que os artigos limitam-se a recolher a impressão de uma certa estranheza causada nos respectivos autores pela vida e pela obra dos artistas abordados.

Rev. Latinoam. Psicopat. Fund., São Paulo, v. 12, n. 2, p. 417-421, junho 2009 

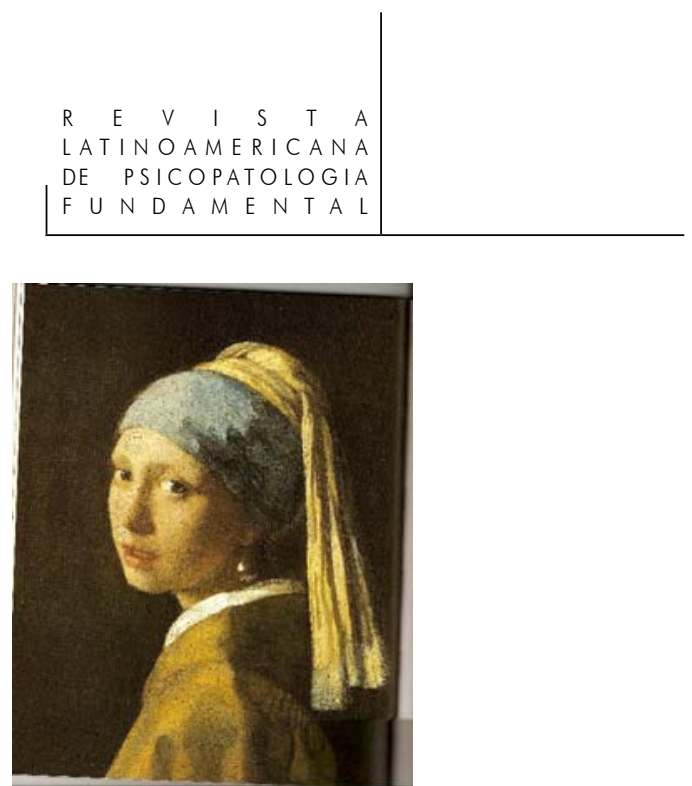

Não um Van Meegeren, mas um autêntico Vermeer

\section{Fora da sala de aula}

Pode-se dizer, com alguma razão, que criticar talvez seja a metade mais fácil do caminho até uma solução mais satisfatória para as relações entre arte e psiquiatria, psicologia ou psicanálise. A insatisfação diante da insuficiência com o tratamento que o tema recebe é, contudo, uma reação natural à leitura desses textos em oposição à sensação do que eles poderiam ser.

Se, nessa direção, a crítica a eles é uma etapa necessária, seria adorável poder oferecer agora o caminho das pedras, ou um pulo do gato que desdobrasse toda a potencialidade que o assunto admite. Todavia, não conheço outra forma de obter resultados interessantes senão através da escolha precisa e apaixonada de um dos tópicos que compõem esse mundo de possibilidades de investigação que é o da arte e da loucura (psicótica ou neurótica). Uma vez feita a escolha, ela deverá ser interrogada, testada e, inevitavelmente, revista ao longo do caminho; o tema deverá ser penetrado sem economia ou moderação, e com muito esforço e alguma sorte pode-se chegar, por caminhos não pavimentados, a alguma coisa diferente daquilo que já se sabia.

Tomando apenas um minúsculo exemplo, o que se tem quando refletimos sobre as imbricações entre a vida e a obra de um determinado artista? Nos artigos da Archives ou do American Journal, as criações aparecem sempre como o produto de uma vida que teria tido tais ou quais particularidades. Mas como ensina Merleau-Ponty (1945) (para não deixar os leitores sem referências bibliográficas mais férteis), em um texto sobre Cézanne: 
A incerteza e a solidão de Cézanne não se explicam, no essencial, por sua constituição nervosa, mas pela intenção da obra. A hereditariedade podia ter-lhe dado sensações ricas, emoções fortes, um vago sentimento de angústia ou de mistério que desorganizassem sua vida voluntária e o separassem dos homens; mas esses dons não fazem uma obra, senão pelo ato de expressão ... Um pintor como Cézanne, um artista, um filósofo devem não penas criar e exprimir uma idéia, mas ainda despertar as experiências que a enraizarão nas outras consciências...

Se nos parece que a vida de Cézanne trazia em germe sua obra, é porque conhecemos a obra primeiro e vemos através dela as circunstâncias da vida, carregando-as de um sentido que tomamos emprestado à obra. (...).

É certo que a vida não explica a obra, mas é certo também que elas se comunicam. A verdade é que essa obra por fazer exigia essa vida. (p. 135136)

Com o exemplo de Merleau-Ponty, deveríamos deixar de lado as réplicas e caminharmos em direção às invenções.

Até a próxima edição!

\section{Outras Referências $\longdiv { 4 2 1 }$}

Merleau-Ponty, M. (1945). A dúvida de Cézanne. In: $O$ olho e o espírito. São Paulo: Cosac \& Naify, 2004. p. 121-142.

. (1961). O olho e o espírito. In: O olho e o espírito. São Paulo: Cosac \& Naify, 2004. p. $13-46$.

\section{Guilherme GutMan}

Psiquiatra e psicanalista; professor adjunto do Departamento de Psicologia da Pontifícia Universidade Católica do Rio de Janeiro - PUC-Rio (Rio de Janeiro, RJ, Brasil)

Rua Visconde de Pirajá, 595/905 - Ipanema

22410-003 Rio de Janeiro, RJ.

Fone: (21) 9106-7009

e-mail: guilhermegutman@gmail.com 